\title{
For the Relief of Suffering
}

\author{
Eric B. Schoomaker, MD, $P h D^{1,2}$ and Chester C. Buckenmaier III, MD ${ }^{1,2}$ \\ 'Department of Military \& Emergency Medicine, F. Edward Hebert School of Medicine, Uniformed Services University of the Health Sciences, \\ Bethesda, MD, USA; ${ }^{2}$ Defense and Veterans Center for Integrative Pain Management, Rockville, MD, USA.
}

KEY WORDS: pain; opioids; epidemic; Department of Defense.

J Gen Intern Med 33(Suppl 1):S9-S10

DOI: $10.1007 / \mathrm{s} 11606-018-4364-3$

(c) Society of General Internal Medicine (outside the USA) 2018

$\mathrm{T}$ he nation currently struggles with one of the most insidious and erosive health epidemics in its history - an epidemic of poorly managed pain that has spawned an opioid crisis. In fact, the health system in this country is immersed in an epidemic of epidemics with each issue spawning other new health crises. This complex emergency involves the misuse and abuse of chronic prescription opioids and opiates, as well as heroin and other illegal street drugs. The crisis has had second-order effects including hepatitis $\mathrm{C}$ from needle sharing, in addition to destroyed families and the staggering loss of human potential derived from the increasing prevalence of addiction or the criminal consequences of addiction and chronic use. It is critically important to retrace the causes of this blossoming "perfect storm" of destructive social and health trends. The Centers of Disease Control and Prevention (CDC) have attributed them to poorly managed chronic pain. ${ }^{1 \text {, }}$ ${ }^{2}$ The magnitude of the national problems emanating from poorly managed chronic pain cannot be understated. Accidental deaths from drug overdoses, half of which now are from prescription opioids, are staggering in number. Between 1999 and 2015 over 183,000 people died from overdoses of these prescription opioids. ${ }^{3,4}$ Prescription opioid deaths are approaching 20,000 a year; in 2016, combined prescription and illicit drug deaths - many of which can be attributed to gateway use of prescription opioids - topped 64,000. Just a few years of these ghastly losses exceed the number of American combat deaths in 15 years of fighting in Iraq and Afghanistan, the U.S. toll from the ten-year war in Vietnam and all of the American non-combat deaths in World War I when the most lethal modern epidemic - the Spanish Flu — was the leading killer. We are fast approaching the peak deaths from the HIV/ AIDS epidemic that occurred in the mid-1990s.

These facts had not gone unrecognized by the Departments of Defense (DoD) and Veterans Affairs (VA). For over a decade, close cooperation between the DoD and VA communities in medical research, medical practice, and policy development have resulted in a shared perspective of the centrality

Published online April 9, 2018 of effective acute and chronic pain management and the need to combine efforts to find best practices and co-develop tools to address pain. This institutional insight began in the mid2000s during the peak of fighting in Iraq and Afghanistan when unprecedented survival from combat wounds, training and other injuries, and serious illnesses was being realized through a concerted effort to improve the protection, lifesaving measures, and recovery and rehabilitation of uniformed service members and veterans. ${ }^{5}$ Attending these improvements in survival and recovery of patients was the development of persistence of often crippling chronic pain - pain too often managed with potent psychotropic drugs and narcotics alone. A variety of internal reports and media stories made clear that many untoward effects of drug treatment were occurring, including accidental overdoses - even deaths - suicides, long-term addictions, and disability. The VA was the first to begin a comprehensive campaign to improve pain management. The DoD followed soon thereafter.

In 2009-2010, the Office of the Army Surgeon General, united with the Navy and Air Force medical services, partnered with the VA in reviewing the extent of problems in managing pain and to adopt a more "whole-person" approach that examined all existing evidence-based approaches and modalities that could be applied. The focus was on the wellbeing of the patient and return to optimal function. The result was the publication in 2010 of a Pain Management Task Force Report and the creation of a DoD pain management strategy to implement the report's 109 recommendations. ${ }^{6}$ The recommendations fell into four broad categories: tools and infrastructure for advancing pain management-including a robust research program; a full spectrum of best practices - including complementary and integrative approaches - to address the continuum of acute and chronic pain; a patient and provider focus to manage pain with the goal of improve function; and synchronizing a culture of pain awareness, education, and proactive intervention. The PMTF Report was followed within a year by a landmark Institute of Medicine Report, Relieving Pain in America-A Blueprint for Transforming Prevention, Care, Education and Research. ${ }^{7}$ It closely mirrored the DoD report and called for a major cultural shift in how pain was understood, prevented, mitigated, and managed.

The past decade since these collective efforts were begun has seen a remarkable degree of formal and informal interagency cooperation as well as public-private partnership in the synchronization of a comprehensive approach to both 
understanding and managing pain. The Departments of Veterans Affairs, Defense, Justice, Health and Human Services - including the National Institutes of Health (National Center for Complementary and Integrative Health $[\mathrm{NCCIH}]$, the National Institute of Drug Abuse [NIDA]), Food and Drug Administration, $\mathrm{CDC}$ - and others have created a variety of forums, research efforts, and coordinated policy approaches to improving pain care and prevent adverse effects of treatment, especially those with opioid medications. Important examples are as follows:

- the joint funding of the development of educational tools and an improved pain rating scale by the VA and DoD (the Defense and Veterans Pain Rating Scale or DVPRS) through a unique Joint Incentive Fund which combined funds from each agency,

- a combined research effort led by the NCCIH and NIDA to use the clinical platforms of the VA and DoD to advance complementary approaches that could be integrated with conventional practices - including the better use of opioids - in pain management, and

- leadership by the DHHS/NIH's Interagency Pain Research Coordinating Council (IPRCC) - with representatives from across the Federal interagency-in codifying the recommendations of the IOM report in a recently published National Pain Strategy.

This remarkable strategic alignment of the Federal health interagency is not without its continuing challenges. The most effective integration of evidence-based complementary practices is best delivered in a patient-centered, team-focused, and multidisciplinary fashion. This runs counter to the current management of pain in most medical settings and is poorly supported by the business model of episodic care that is workload based and procedure oriented in the majority of cases. A model of reimbursement that rests upon optimal clinical outcomes and value for the patient, especially regarding return to function, must be developed. Furthermore, the communities of complementary and integrative practitioners and their respective disciplines suffer from unfounded though widespread skepticism from the medical establishment about the scientific basis for and evidence of effectiveness of their impact on pain relief and functional improvement. Despite considerable quality evidence to the contrary, too many within the conventional medical community consider integrative medicine unproven at best and its practitioners sham artists at worst.

This special publication is intended to address the emerging science underlying the use of these complementary practices that can be effectively integrated with many conventional approaches to pain. Integrative medicine is not an alternative to conventional approaches; rather, these tools are equal and synergistic partners to established pain medicine practices expanding care options for patients at a time when they are desperately needed. Having committed to proactively embracing mind-body modalities for the promotion of health and well-being, including in the treatment of pain, the VA understands the need to continue to invest in quality research to build the evidence base for their use. Those of us in the larger Federal health system who have been a part of this important cultural change are grateful for the leadership of so many of our VA and other civilian partners. We remain optimistic that the suffering that so often accompanies pain may be lifted, for the betterment of all-patient, family, community, and practitioner alike. To paraphrase one of the fathers of modern pain treatment John J. Bonica: "The proper management of pain remains, after all, the most important obligation, the main objective, and the crowning achievement of every physician... and caregiver." 8

Corresponding Author: Chester C. Buckenmaier, III, MD; Department of Military \& Emergency Medicine F. Edward Hebert School of Medicine, Uniformed Services University of the Health Sciences, Bethesda, MD, USA (e-mail: cbuckenmaier@dvcipm.org).

\section{Compliance with Ethical Standards:}

Federal Medicine Disclaimer: Any opinions, findings and conclusions or recommendations expressed are those of the authors and should not be construed as an official Department of Defense or Uniformed Services University of the Health Sciences position, policy, or decision.

\section{REFERENCES}

1. Quinones S. Dreamland. New York: Bloomsbury Press; 2015.

2. Paulozzi L, Jones C, Mack K, et al. Vital signs: overdoses of prescription opioid pain relievers-United States, 1999-2008. MMWR 2011; 60(43): 1487-1492.

3. CDC. Wide-ranging online data for epidemiologic research (WONDER). Atlanta, GA: CDC, National Center for Health Statistics; 2016. Available at http://wonder.cdc.gov.

4. Rudd R, Seth P, David F, Scholl L. Increases in Drug and Opioid-Involved Overdose Deaths - United States, 2010-2015. MMWR Morb Mortal Wkly Rep. ePub: 16 December 2016. doi: https://doi.org/10.15585/mmwr. mm6550e1. Accessed 26 Dec 2017.

5. Kellermann A, Elster E. eds. Out of the Crucible: How the US Military Transformed Combat Casualty Care in Iraq and Afghanistan. U.S.Army: Borden Institute; 2017

6. Pain Management Task Force Final Report: Providing a Standardized DoD and VHA Vision and Approach to Pain Management to Optimize the Care for Warriors and their Families. Office of the Army Surgeon General: Pain Management Task Force; 2010.

7. Institute of Medicine. Relieving Pain in America: A Blueprint for Transforming Prevention, Care, Education, and Research. Washington, DC: The National Academies Press; 2011.

8. Bonica, J. The Management of Pain (2 Volumes). 2nd ed. Philadelphia: Lea \& Febiger; 1990. 